\title{
Autoconsciência e conceito no pensamento tardio de Fichte e na Lógica de Hegel
}

Christian Klotz

\section{(2) OpenEdition}

Journals

Edição electrónica

URL: http://journals.openedition.org/ref/705

DOI: $10.4000 /$ ref.705

ISSN: 2258-014X

Editora

EuroPhilosophie Editions

Refêrencia eletrónica

Christian Klotz, « Autoconsciência e conceito no pensamento tardio de Fichte e na Lógica de Hegel », Revista de Estud(i)os sobre Fichte [Online], 13 | 2017, posto online no dia 01 março 2017, consultado o 10 dezembro 2020. URL : http://journals.openedition.org/ref/705 ; DOI : https://doi.org/10.4000/ref. 705

Este documento foi criado de forma automática no dia 10 dezembro 2020

(c) EuroPhilosophie 


\title{
Autoconsciência e conceito no pensamento tardio de Fichte e na Lógica de Hegel
}

\author{
Christian Klotz
}

Em 1812 Fichte proferiu pela primeira vez uma preleção sob o título "Sobre a relação da lógica com a filosofia ou lógica transcendental". o fato de que Fichte se dedicou a questões acerca da relação entre filosofia e lógica no mesmo ano no qual o primeiro volume da Lógica de Hegel foi publicado levou alguns intérpretes a supor que a preleção de Fichte foi ocasionada pela publicação da obra de Hegel. Segundo essa hipótese, na preleção de 1812 Fichte implicitamente se refere à Lógica de Hegel e à concepção de filosofia nela envolvida. ${ }^{1}$ Essa hipótese parecia receber certa corroboração quando ficou conhecido o manuscrito da primeira parte da preleção - apresentada por Fichte no verão de 1812 - que foi publicado pela primeira vez em 2006 na J.G Fichte-Gesamtausgabe. ${ }^{2}$ Numa observação de agosto de 1812 - o primeiro volume da Lógica de Hegel tinha sido lançado na feira da páscoa do mesmo ano - Fichte refere-se a um "novo filosófo" (ein neuer philosophischer Schriftsteller) que teria feito a tentativa de restabelecer o "dogmatismo" e que utilizaria "artifícios" (Kunststïke) para construir uma passagem lógica do Ser para a mudança - passagem esta que Fichte considera impossível. ${ }^{3}$ Reinhard Lauth, um dos editores do manuscrito, defendeu a tese de que o alvo dessa observação é Hegel. Que em 1812 Hegel era para Fichte ainda um "novo filosófo" é, segundo Lauth, plausível se levamos em consideração que os escritos críticos publicados por Hegel na sua fase ienense para Fichte não contavam como contribuições propriamente sistemáticas e que, por tudo que parece, Fichte não tinha tomado conhecimento da existência da Fenomenologia do Espírito. ${ }^{4}$ A tese de Lauth até hoje continua sendo polémica. No entanto, não se pretende discutir aqui a questão histórica de se Fichte na observação citada do manuscrito do verão de 1812 se refere a Hegel, ou a algum outro autor. Em vez disso, pretende-se elucidar sob o aspecto sistemático a relação entre a lógica transcendental de Fichte do verão de 1812 e a Lógica de Hegel. Para tal, no que segue defende-se duas teses: primeiro, que apesar de o pensamento de Fichte em 1812 ter mais afinidade com o de Hegel do que nas versões ienenses da 
Doutrina da Ciência, a principal intenção sistemática da sua lógica transcendental é oposta à da Lógica de Hegel. Segundo, que para compreender a relação sistemática da lógica transcendental de Fichte com a Lógica de Hegel é preciso relacioná-la com a parte final da obra hegeliana, isto é, com a Doutrina do Conceito (e não, como sugerido por alguns intérpretes, com a Doutrina da Essência). Para argumentar em favor dessas duas teses é preciso primeiro identificar alguns elementos centrais da investigação sobre a relação entre a lógica e a filosofia apresentada por Fichte no verão de 1812.

\section{Conceito e Eu lógico na preleção Transzendentale Logik I}

2 A preleção de Fichte do verão de 1812 tem por objetivo introduzir ao ponto de vista da filosofia ao esclarecer sua diferença com o ponto de vista da lógica. Mais precisamente, Fichte busca mostrar que os pontos de vista da lógica e da filosofia são opostos. $O$ fato de que a lógica tem forte influência na cultura e na formação acadêmica segundo Fichte prejudica a filosofia, uma vez que os pressupostos dogmáticos da lógica fazem com que as questões fundamentais da filosofia não sejam mais compreendidas. ${ }^{5}$ Para esclarecer a diferença entre os dois pontos de vista, Fichte considera questões que a lógica e a filosofia têm em comum, buscando mostrar em que medida suas abordagens sobre essas questões divergem. Uma questão que, segundo Fichte, é central para ambas é a da natureza do pensamento. Consequentemente, a questão de qual o caráter fundamental do nosso pensamento está em foco em todas as partes da preleção fichteana. No que segue, consideramos dois aspectos que possuem um lugar central na preleção do verão de 1812: primeiro, a diferença entre as concepções lógica e filosófica do conceito; e, segundo, a diferença entre a lógica e a filosofia na compreensão do sujeito pensante, ou seja, da consciência 'Eu penso'.

3 A concepção lógica do conceito, tal como ela é apresentada por Fichte, baseia-se na ideia de que conceitos são produtos da abstração. Nessa concepção supõe-se que há um múltiplo dado que é pré-conceitual e que o pensamento forma um conceito ao abstrair de certas características envolvidas no múltiplo dado, unindo as restantes características num conceito. O principal argumento de Fichte contra a teoria da abstração é que sua explicação acerca da origem dos conceitos é circular. Isso fica claro quando perguntamos como é que o sujeito da abstração sabe de quais das características contidas no múltiplo dado ele deve abstrair e quais ele deve incluir no conceito a ser formado. $O$ processo de abstração precisa de uma regra que o oriente. $\mathrm{E}$ essa regra, Fichte argumenta, não pode ser outra coisa senão o conceito mesmo. Pois o que, senão o conceito, pode me dizer quais são as características que devo focalizar num múltiplo dado para chegar ao conjunto de características que constitui o seu conteúdo? No entanto, com esse resultado mostra-se que a teoria da abstração enquanto teoria acerca da origem de conceitos é circular - ela pressupõe que o sujeito da abstração já dispõe do conceito a ser formado pela abstração. ${ }^{6}$

4 Fichte não quer negar com seu argumento contra a teoria da abstração que a concepção lógica da abstração se refere a um fenômeno real que está envolvido em nosso uso de conceitos. Pois acontece que, através de percepções posteriores e semelhantes, nos tornamos conscientes de uma determinação originalmente apresentada numa percepção como uma determinação que pode se repetir na experiência, sendo, nesse sentido, 'geral'. Há então um processo no qual ficamos conscientes de uma 
determinação como um conteúdo geral que pode ser separado do contexto concreto da sua primeira instanciação, e tal processo pode ser caracterizado como 'abstração'. No entanto, a abstração assim entendida não gera a determinação conceitual como tal, mas apenas dá origem à consciência da sua separabilidade de situações perceptuais concretas, isto é, do seu caráter geral ou abstrato. Pela abstração, diz Fichte "o conceito não é produzido, mas apenas reconhecido como repetindo-se nesta intuição" $\mathrm{O}$ argumento fichteano contra a teoria lógica da abstração exemplifica uma tese geral que é decisiva para a crítica da lógica formulada por Fichte nas preleções do verão de 1812: a lógica considera como origem última (nesse caso: de conceitos) o que na verdade é apenas um fenómeno secundário. Nesse sentido, seu ponto de vista é o da "empiria". Em contraste com isso, na filosofia aquilo que na lógica é considerado fundamental é explicado - o que na lógica é 'princípio', para a filosofia é apenas 'principiado'.

Levanta-se com isso a questão de qual a teoria adequada acerca da origem dos conceitos que deve ser adotada na filosofia, excluindo-se a teoria da abstração. É em relação com essa questão que Fichte formula o que ele considera a concepção propriamente filosófica do pensamento. Conceitos, diz Fichte, estão envolvidos em toda consciência. Pois estamos conscientes de conteúdos perceptuais 'como algo'. O conteúdo perceptual, como Fichte diz, sempre possui um determinado "caráter" (Charakter), e esse fato implica que a percepção sempre envolve um conteúdo conceitual. É "absolutamente impossível", diz Fichte, "que haja algum fenómeno sem conceito". ${ }^{9}$ 'não-conceito', o dado pré-conceitual que a teoria lógica da abstração pressupõe (como podemos dizer aqui citando Sellars) é um mito. ${ }^{10}$ Inversamente, conceitos essencialmente referem-se a intuições que são subsumidas sob eles. Nesse sentido, conceitos são "modos de ver" (Ansichten) ou "imagens" (Bilder) de algo que se compreende através deles. No entanto, como Fichte diz com referência explícita a Platão, imagens eles são enquanto "arquétipos" (Urbilder), porque são constitutivos do que o fenómeno consciente é para nós. ${ }^{11} \mathrm{O}$ fato de que, nesse sentido, a consciência é "a unidade orgânica do conceito e da intuição" 12 implica que a questão da origem dos conceitos é inseparável da questão da origem da consciência. E disto se segue que deve haver um pensamento que, ao produzir conceitos, ao mesmo tempo gere a própria consciência - resultado este que Fichte considera essencial para a compreensão filosófica da natureza do pensamento.

Para entender a natureza desse pensamento, segundo Fichte é preciso levar em consideração o caráter holístico da determinação conceitual. Tal determinação existe só dentro de um "sistema" de determinações, porque ela é essencialmente constituída pela negação de outras determinações. Fichte conclui disto que conceitos são formados por um pensamento "absoluto" que gera um todo holístico de determinações. E porque isso implica que o conteúdo de todos os conceitos é produzido pelo pensamento, Fichte diz que todos os conceitos são 'a priori' ${ }^{13}$ Como consequência disso, Fichte defende que conceitos novos não surgem na consciência pela abstração baseada em dados préconceituais, mas a partir de uma conceitualização anterior da realidade, isto é, como ampliação do sistema conceitual já existente. O surgimento de conceitos novos, diz Fichte, é essencialmente "ampliação do reino do entender" (Erweiterung des Reichs des Verstehens).$^{14}$ Com isso, Fichte chega a uma das principais teses da sua abordagem sobre a natureza de conceitos na prelação do verão de 1812, que ele formula do seguinte modo: "Minha intenção é mostrar-lhes que também os conceitos do real que ocorrem na empiria são absolutamente a priori, isto é, fazem a si mesmos no saber, pelo saber e por suas leis internas, sem a influência de qualquer princípio alheio fora do saber." ${ }^{15} \mathrm{~A}$ ênfase que Fichte dá ao caráter absoluto do pensamento que gera os conteúdos 
conceituais da consciência leva-nos ao segundo elemento da preleção do verão de 1812 que deve ser destacado aqui: a concepção fichteana do Eu lógico, ou seja, da consciência 'Eu penso'.

7 A tese de que há um pensamento originário que gera a totalidade holística dos conteúdos da consciência tem por consequência que também o 'Eu' deve ser entendido como produto desse pensamento. Por isso, Fichte considera a "fundamentação do fenómeno do Eu lógico" (Begründung des Phänomens [des] logischen Ich) uma tarefa essencial da filosofia. ${ }^{16} \mathrm{~A}$ explicação genética da egoidade que é desenvolvida na preleção de 1812 baseia-se na ideia de que o pensamento é essencialmente capaz de refletir, isto é, de compreender a si mesmo. o pensamento, diz Fichte, é caracterizado pela "reflexibilidade" (Reflexibilität). ${ }^{17} \mathrm{E}$ na medida em que o pensamento não apenas reflete, mas também se torna consciente da reflexão como sua atividade essencial, o pensamento pensa a si mesmo como 'Eu' no sentido de uma instância que é caracterizada pela identidade entre o pensante e o que é pensado. Portanto, o Eu consciente não é outra coisa senão uma imagem do seu próprio caráter reflexivo que é produzida pelo pensamento. ${ }^{18}$

8 Com base na sua explicação genética do Eu lógico, Fichte critica a concepção do Eu pensante que seria adotada pela lógica, reafirmando com isso a intenção geral da preleção de 1812 de destacar a oposição entre os pontos de vista lógico e filosófico. Segundo Fichte, a lógica entende os atos do pensamento aos quais ela se refere - por exemplo, a atividade de abstrair - como atos de um Eu pensante. Assim, na sua compreensão do pensamento, a lógica mantem-se no ponto de vista da consciência ' $\mathrm{Eu}$ penso' a qual é considerada como um dado último. Com isso mostra-se novamente que a lógica considera como condições últimas do pensamento fenómenos que na filosofia são explicados geneticamente (que a lógica considera 'princípio' o que na filosofia é 'principiado'). Na explicação genético-filosófica que parte do pensamento originário que constitui a própria consciência, evidencia-se que o Eu consciente não é o autor do pensamento, mas seu produto, ou seja, uma imagem da sua capacidade de refletir que é produzida pelo próprio pensamento. Portanto, o pensamento originário ao qual a filosofia essencialmente se refere "não é pensado por algum Eu", mas ocorre "absolutamente". ${ }^{19}$ A consciência de si como autor do pensamento na filosofia evidencia-se como "ilusão" (Schein), no entanto, uma ilusão que não pode ser suprimida ou eliminada (não podemos pensar sem estarmos conscientes de nós), mas que pode ser compreendida como ilusão, deixando assim de dar origem a ilusões acerca da natureza do pensamento. ${ }^{20}$

\section{O construtivismo do "pensamento absoluto" e sua superação na Doutrina da Ciência}

9 Tanto na sua crítica da concepção lógica do conceito, como na do pressuposto lógico do Eu como autor do pensamento, Fichte defende a noção de um pensamento originário que é gerador da estrutura da consciência como uma concepção que é fundamental para a filosofia. É tal concepção que segundo Fichte define o próprio ponto de vista da filosofia, tornando-a capaz de explicar geneticamente os pressupostos dogmáticos da lógica. Com isso, a compreensão fichteana da filosofia envolve uma posição radicalmente construtivista. Qualquer determinação que podemos entender, e a totalidade de tais determinações, é um produto do 'saber' no sentido do pensamento 
originário. Como consequência disso, Fichte diz que a natureza enquanto totalidade das determinações aparentemente 'dadas' não é outra coisa senão "imagem" (Bild). ${ }^{21}$ Mais precisamente: a natureza é uma imagem projetada que parece uma realidade independente, mas que em verdade é apenas um produto do saber. No entanto, não seria adequado reduzir a concepção do saber que é desenvolvida na Doutrina da Ciência do Fichte tardio a um construtivismo radical. Já na primeira apresentação da Doutrina da Ciência que inaugura sua fase tardia em Berlim, na Doutrina da Ciência de 1810, Fichte caracteriza a visão construtivista do saber como um "idealismo" que é um "niilismo", na medida em que tal concepção priva os objetos comuns de qualquer modo de ser que seja independe, ou 'por si'. "Se a Doutrina da Ciência terminasse aqui, se ela não soubesse dizer nada mais, ela seria um niilismo [...]. O mundo estaria aniquilado; nada outro estaria dado", diz Fichte em 1810. ${ }^{22}$ Fichte claramente incorpora aqui, no argumento da própria Doutrina da Ciência, a crítica de Jacobi ao idealismo da Doutrina da Ciência. E o argumento que começa nesse ponto - ou seja, a maior parte da apresentação da Doutrina da Ciência de 1810 - pode ser considerado como a resposta do Fichte tardio à crítica da Doutrina da Ciência que em 1799 tinha sido formulada por Jacobi. ${ }^{23}$

10 Em que consiste a resposta tardia de Fichte a Jacobi? A tese que é central para todas as versões da Doutrina da Ciência apresentadas a partir de 1810 está diretamente relacionada com o objetivo de superar a visão construtivista do saber que, segundo Fichte, vale para nossa relação cognitiva com objetos empíricos: a Doutrina da Ciência busca mostrar que e como o saber pode entender a si mesmo como 'imagem do Ser', o Ser sendo entendido como aquilo que é por si, não podendo ser entendido como construto ou projeção do saber. Fichte deixa claro que o Ser é um só - o Absoluto ou Deus - e que todo outro apenas deve ser entendido como sua imagem ou sua aparição. Neste ponto, Fichte vê-se em plena concordância com Espinosa, no entanto, com uma ressalva importante: o Ser, Fichte objeta, não pode receber nenhuma modificação - ao contrário do que Spinoza teria defendido na sua teoria dos atributos e modos. ${ }^{24}$ Portanto, o Ser está situado além de qualquer determinação. A determinação encontrase só na sua aparição que possui uma "vida própria", ou seja, que se estrutura autonomamente. ${ }^{25} \mathrm{E}$ justamente essa atividade autopoiética é o pensamento originário que Fichte põe em foco na sua preleção introdutória do verão de 1812 - o pensamento que gera a estrutura holística dos conteúdos da consciência e o Eu pensante como imagem do seu caráter reflexivo. No entanto, o destino próprio desse pensamento é compreender a si mesmo como aparição ou imagem do Ser, relacionando-se desse modo com algo que não é construído por ele mesmo. Desse modo, a Doutrina da Ciência busca ir além do idealismo, isto é, além do construtivismo, no entanto, sem ser uma "Doutrina do Ser" (Seinslehre). ${ }^{26} \mathrm{Em}$ vez disso, a Doutrina da Ciência investiga as condições que possibilitam ao saber transcender a si mesmo justamente através da sua capacidade de refletir e entender a si mesmo como imagem viva de uma instância que não pode ser entendida como construto gerado pela sua própria atividade. 


\section{Conceito e autoconsciência na lógica transcendental de Fichte e na doutrina hegeliana do conceito}

11 Na medida em que o conceito de 'Ser' possui um papel fundamental na filosofia tardia de Fichte, tornando-se o ponto de partida próprio da exposição da Doutrina da Ciência, parece que há uma proximidade com o pensamento hegeliano - mais precisamente: com o início da Lógica de Hegel. No entanto, é inegável que há ao mesmo tempo uma diferença profunda entre a concepção fichteana do Ser e a de Hegel: o Ser, Fichte enfatiza contra Espinosa, não pode ter nenhuma determinação, nenhum atributo ou modo. Determinação e processualidade só podem ocorrer na sua aparição. Assim, a relação entre o Ser e sua imagem (ou aparição) torna-se central para o pensamento tardio de Fichte. Com isso, do ponto de vista da lógica hegeliana, o pensamento do Fichte tardio parece manter-se dentro das estruturas da Doutrina da Essência, o que foi observado por intérpretes como Angelica Nuzzo e Christoph Asmuth. ${ }^{27}$

No entanto, cabe observar que a posição do Fichte tardio, embora certamente ela tenha seu foco na relação entre o Ser e sua aparição, envolve uma abordagem muito peculiar acerca de tal relação. Ao buscar reconstruir sua "vida própria", a investigação fichteana da aparição torna-se uma teoria da auto-estruturação do saber que destaca seu caráter autopoiético: o saber gera sua relação teórica e prática com o mundo e consigo mesmo espontaneamente por si mesmo. 0 objetivo dessa explicação 'idealista' do saber é a desontologização de toda determinação, que é completamente reduzida a imagens ou produtos do pensamento. ${ }^{28} \mathrm{~A}$ função dessa produção de imagens pelo saber segundo Fichte é possibilitar que o saber finalmente se compreenda como imagem do próprio Ser, este sendo a única instância que não é imagem, ou seja, que não é construída. É verdade que na sua hostilidade ontológica à determinação, a posição do Fichte tardio claramente contradiz a todo o desenvolvimento pelo qual na Lógica de Hegel a concepção inicial do Ser é revisada e progressivamente concretizada. Mas na medida em que ela envolve uma teoria altamente complexa acerca da autoconstituição do saber e das condições da sua autocompreensão como imagem do Ser, a filosofia tardia de Fichte também não corresponde exatamente à concepção hegeliana do pensamento que é caracterizado pelas categorias da Doutrina da Essência.

13 No entanto, a apresentação dos elementos centrais da preleção fichteana do verão de 1812 que foi dada acima aponta para a possibilidade de entender a relação sistemática entre a concepção fichteana da lógica transcendental e a Lógica de Hegel de outra maneira do que pela hipótese da correspondência entre o pensamento do Fichte tardio e a metafísica da essência conforme concebida (e criticada) na lógica hegeliana. Talvez seja mais frutífero relacionar o pensamento tardio de Fichte não com a Doutrina da Essência, mas com a parte final da Lógica de Hegel, a Doutrina do Conceito. Com efeito, nesta última, as duas questões que foram focalizadas aqui na discussão da preleção de Fichte - a natureza do conceito e da autoconsciência - estão intrinsecamente ligadas: na seção introdutória "Sobre o conceito em geral", Hegel não apenas explicita a estrutura geral do conceito, apresentando desse modo o "conceito do conceito", mas também volta-se para a autoconsciência como concretização do conceito "na medida em que cresceu para uma existência que é ela mesma livre". ${ }^{29}$ Comparando as abordagens fichteana e hegeliana sobre o conceito e a autoconsciência nas respectivas obras, podemos observar que elas têm dois motivos em comum: primeiro, Fichte e 
Hegel criticam a concepção do conceito que é adotada pela lógica formal, a fim de mostrar que é só na filosofia que a verdadeira natureza do conceito se revela; segundo, Fichte e Hegel buscam compreender a autoconsciência com base em aspectos mais fundamentais, negando seu lugar fundamental na filosofia. A consciência 'Eu penso' não é o princípio da filosofia, mas um fenômeno que só pode ser compreendido com base em uma concepção formulada em termos não-egológicos.

No entanto, mesmo que o Fichte tardio e o Hegel da Lógica convirjam sob o aspecto do objetivo geral da sua explicação filosófica da natureza do conceito e da autoconsciência, no que diz respeito à concepção que é considerada sistematicamente fundamental e à própria natureza da explicação filosófica que é adotada para compreender o conceito e a autoconsciência, há uma divergência profunda. Fichte busca explicar o conceito, no sentido da lógica formal, e o $\mathrm{Eu}$ do Eu penso geneticamente como produtos do pensamento originário que constitui a consciência, desse modo 'desontologizando' tanto a determinidade dos conceitos como a autoconsciência. O conteúdo conceitual e o Eu do Eu penso são "imagens", isto é, produtos do pensamento que representam algo diferente deles mesmos.

Em contraste com isso, a lógica hegeliana focaliza uma questão estrutural: segundo Hegel, a autoconsciência e o conceito no sentido da lógica formal - o conceito enquanto "representação abstrata" - só podem ser adequadamente compreendidos a partir da concepção da unidade originária da universalidade e da particularidade que emerge na passagem da Doutrina da Essência para a Doutrina do Conceito. Essa concepção - o "conceito do conceito" no sentido filosófico-especulativo - envolve a noção de uma "manifestação que se tornou inteiramente livre", isto é, de uma identidade que se constitui justamente pela atuação própria das determinações particulares na qual ela se manifesta. ${ }^{30}$ Assim, na concepção especulativa do conceito, a concepção de uma identidade imediata e "interna" que subjaz às determinações particulares (a identidade como "essência") é superada pela noção de uma identidade superordenada que emerge só com o processo no qual ela se manifesta nas determinações "externas". É no sentido de tal sucessor lógico da identidade da essência que Hegel fala da "universalidade" como um momento do conceito que é inseparável da particularidade, isto é, da sua manifestação "externa".

Hegel analisa a autoconsciência como concretização consciente da estrutura do conceito, referindo-se nesse contexto explicitamente à concepção kantiana da consciência Eu penso. ${ }^{31}$ Concordando nesse ponto com Kant, Hegel defende que a autoconsciência pura do sujeito pensante envolve uma consciência da própria identidade que difere de qualquer determinidade empírica. No entanto, observa Hegel, a consciência de tal identidade não é imediata - ela se forma pela atividade da consciência individual, na medida em que pessoas na sua autocompreensão se distanciam das suas determinações empíricas. A identidade pura do 'Eu' constitui-se pela atividade do sujeito particular, pela "negatividade" da qual ele é capaz em relação às suas próprias determinações empíricas. Portanto, a identidade consciente é "universalidade" no sentido que caracteriza o conceito - uma identidade que se forma pela sua manifestação no particular, manifestação esta que é um livre exercício do próprio ser particular. Assim, Hegel pode identificar a estrutura da autoconsciência com a do conceito - o eu "é o puro conceito mesmo" 32 .

Hegel considera a estrutura do conceito também a chave para a compreensão filosófica do conceito no sentido da lógica formal, isto é, de representações abstratas sob as quais 
se subsumem objetos singulares. É nesse contexto que se pode falar de "conceitos" no plural, enquanto a concepção especulativa do conceito exige o singular "o conceito", significando uma estrutura que pode efetuar-se de várias maneiras na natureza e na vida do espírito. Obviamente, os dois conceitos do conceito são muito diferentes. ${ }^{33}$ Do ponto de vista da compreensão especulativo-filosófica do conceito, a concepção do conceito como representação abstrata não capta o sentido mais fundamental da palavra "conceito". Hegel dá expressão à relação crítica do pensamento especulativo com a compreensão comum do conceito ao dizer que o que se costuma entender por "conceito" é o "conceito sem conceito" (begrifflose Begriff). ${ }^{34}$ No entanto, Hegel não apenas enfatiza a diferença entre as duas concepções do conceito. É uma tese central da Doutrina do Conceito que há uma relação explicativa e filosoficamente significativa entre o conceito como unidade processual do universal e do particular e o conceito enquanto representação abstrata. $O$ pensamento é capaz de separar as determinações particulares da efetividade processual na qual elas estão envolvidas e fixá-las como conteúdos "imutáveis" que possuem uma identidade estática. Desse modo, as determinações particulares tornam-se "abstratas", isto é, tornam-se determinações separadas da realidade concreto-processual na qual existem só como momentos da efetuação do conceito no sentido especulativo. E na medida em que o pensamento opera com determinações abstratas como elementos últimos da sua compreensão da realidade, ele entende sua própria atividade como sendo essencialmente a subsunção de objetos sob tais determinações. Hegel chama de "entendimento" o pensamento na medida em que compreende a si mesmo como atividade subjetiva de subsumir objetos singulares sob conceitos no sentido de representações que possuem um conteúdo fixo e abstrato. Nesse ponto de vista, o pensamento perde o sentido fundamental no qual o conceito é "universal": não como determinação abstrata sob a qual se pode subsumir objetos singulares, mas como identidade processualmente constituída, diante da qual determinações particulares são apenas "momentos" da sua efetuação. Hegel defende que só na medida em que ele se orienta pelo "conceito do conceito" no sentido especulativo, o pensamento é capaz de apropriar-se da realidade, ou seja, de compreender sua verdadeira constituição dinâmica, em vez de apenas classificá-la externamente. Por outro lado, ao pensar a efetividade através de conceitos abstratos, o entendimento possui o mérito de focalizar a determinação particular que é um aspecto indispensável da realidade: "Além disso", diz Hegel, "deve ser considerada a força infinita do entendimento que ele divida o concreto nas determinações abstratas e compreenda a profundidade da diferença ..." ${ }^{35}$ Assim, ao adotar a concepção do conceito no sentido não-especulativo que se refere a representações abstratas ou "conceitos determinados", a lógica formal reflete um aspecto do pensamento que é essencial para nossa compreensão da realidade. No entanto, ela distorce nossa visão da realidade quando ela é entendida como trazendo a verdade última sobre a natureza do pensamento e do conceito. $\mathrm{O}$ ponto de vista da lógica formal precisa ser explicado a partir da concepção filosófico-especulativa do conceito, e justamente isso é um objetivo central da doutrina hegeliana do conceito. ${ }^{36}$

18 A partir de 1812, em Fichte e em Hegel, duas figuras radicalmente diferentes da ideia de uma lógica filosófica começam então a desenhar-se: uma teoria genética e desontologizante (Fichte) e uma teoria ontológica baseada na concepção do conceito como estrutura originária da realidade e do nosso pensamento (Hegel). No entanto, para se entender a possível relevância desse resultado, é preciso inseri-lo numa perspectiva mais geral. A trajetória do idealismo alemão hoje não costuma mais ser 
vista como um desenvolvimento teleológico 'de Kant a Hegel' no qual Fichte seria apenas um pensador intermediário. Em particular a filosofia tardia de Fichte, que só mais recentemente ficou accessível à pesquisa, não pode ser considerada uma mera etapa intermediária e ultrapassada pelo pensamento especulativo de Hegel. Como Dieter Henrich observou, as posições de Kant, do Fichte tardio e de Hegel "permanecem abertas como possíveis abordagens filosóficas". ${ }^{37} \mathrm{O}$ objetivo deste artigo foi contribuir para a compreensão da relação entre o pensamento do Fichte tardio e de Hegel no sentido de uma alternativa ainda aberta. ${ }^{38}$

\section{Referências bibliográficas}

Asmuth, Christoph, "Das Wesen als Reflexion in ihm selbst" - Fichte in Hegels

Wesenslogik", in: Wunsch, Matthias (org.), Von Hegel zur philosophischen Anthropologie. Gedenkband für Christa Hackenesch, Würzburg

2012, pp. 73-85

Carvalho, Mario Jorge, "What it takes to make an image. From Fichte's thinking Workshop (his Diary entry for the $25^{\text {th }}$ October 1813)", in: Rivista di Storia della Filosofia 4 , 2014, pp. 701-735

Düsing, Klaus, Das Problem der Subjektivität in Hegels Logik, Bonn: Bouvier 1995

Fichte, Johann Gottlieb, Gesamtausgabe der Bayerischen Akademie der Wissenschaften, ed. por Reinhard Lauth e Hans Gliwitzky, Stuttgart-Bad Cannstatt: Frommann-Holzboog 1962 ss. (= GA)

23 ---, Die späten wissenschaftlichen Vorlesungen I. 1809-1811, ed. por Hans Georg von Manz e.a., Stuttgart-Bad Cannstatt 2000 (= SWV I)

Hegel, Georg Wilhelm Friedrich, Gesammelte Werke. In Verbindung mit der Deutschen Forschungsgemeinschaft herausgegeben von der Rheinisch-Westfälischen Akademie der Wissenschaften. Hamburg: Meiner 1968 ss. (= GW)

25 ---, Ciência da Lógica. Excertos. Seleção e tradução de Marco Aurélio Werle, São Paulo: Barcarolla 2011 Henrich, Dieter, Between Kant and Hegel: lectures on German idealism, Cambridge: Harvard University Press 2003 Iber, Christian, “Hegels Konzeption des Begriffs", in: Koch, Anton Friedrich/Schick, Friedrike (org.), G.W.F. Hegel. Wissenschaft der Logik, Berlin: Akademie Verlag 2002, pp. 181-201 Fichte-Studien 14, 1998, pp. 107-119 Reisinger, Peter, Idealismus als Bildtheorie. Untersuchungen zur Grundlegung einer Zeichenphilosophie, Stuttgart: Klett-Cotta 1979 Kant, Immanuel, Crítica da Razão Pura, tradução de Fernando Costa Mattos, Petrópolis: Editora Vozes 2012

31 Lauth, Reinhard: "Eine Bezugnahme Fichtes auf Hegels „Wissenschaft der Logik“ im Sommer 1812", in: Kant-Studien, vol. 89, 1998, pp. 456-464

32 McDowell, John: Mind and World. Cambridge: Harvard University Press $1996^{2}$ 
33 Quante, Michael e Siep, Ludwig (org.): Heges Erbe, Frankfurt: Suhrkamp 2004, pp. 184-208

34 ---, Having the world in view. Essays on Kant, Hegel and Sellars. Cambridge: Harvard University Press 2013

Nuzzo, Angelica: “Fichte's 1812 Transcendental Logic - Between Kant and Hegel”, in: Fichte-Studien, vol. 30, 2006, pp. 163-172

\section{NOTAS}

1. Ver, por exemplo, Widmann 1982, p. 37 e 44.

2. Ver GA II, 14, pp. 1-151.

3. GA II, 14, p. 140/141.

4. Ver Lauth 1998, pp. 460-464.

5. Ver, por exemplo, GA II, 14, p. 15.

6. Para o argumento de Fichte contra a teoria da abstração, ver particularmente GA II, 14, p. 28-30

7. "Und so wird denn durch diese Abstraktion der Begriff nicht erzeugt, sondern er wird nur als ein sich in dieser Anschauung wiederholender anerkannt” (GA II, 14, p. 32).

8. Ver, por exemplo, GA II, 14, pp. 10/11.

9. "Aber es ist schlechthin unmöglich, daß irgend eine Erscheinung überhaupt ohne Begriff sey" (GA II, 14, p. 30).

10. Fichte refere-se explicitamente ao 'não-conceito' (Nichtbegriff), isto é, ao dado pré-conceitual como pressuposto da teoria lógica da abstração, antecipando a crítica do "mito do dado" que foi formulada por W. Sellars e mais recentemente retomada por J. McDowell (GA II, 14, p. 18). Se a relação da tese defendida por McDowell (acerca do caráter conceitual do conteúdo perceptual) com as posição de Kant e Hegel já foi amplamente discutida (inclusive pelo próprio McDowell), a relação do pensamento de Fichte com a concepção da percepção que é adotada por McDowell ainda não foi investigada (ver McDowell 1994, 2004 e 2013).

11. Ver GA II, 14, particularmente pp. 19 e 27.

12. GA II, 14, p. 28.

13. Ver GA II, 14, por exemplo, pp. 26, 28 (“die Apriorität schlechthin aller Begriffe") e 33.

14. GA II, 14, p. 31.

15. "Meine Absicht ist, Ihnen zu zeigen, daß auch die Begriffe des in der Empirie vorkommenden wirklichen, schlechthin apriorisch sind, d.i. im Wissen, durch das Wissen u. dessen innere Gesetze sich selbst machen, ohne Zuthun irgend eines fremden Princips außer dem Wissen" (GA II, 14, p. 26).

16. GA II, 14, p. 11.

17. Ver GA II, 14, particularmente pp. 80, 86 e 142.

18. Para a dedução da "forma do Eu" (Ichform) na preleção do verão de 1812, ver particularmente GA II, 14, pp. 87-91.

19. "Das Denken, das ursprüngliche nemlich u. absolute, das nicht gedacht wird durch irgend ein Ich, sondern welches schlechthin ist ...” (GA II, 12, p. 14). 
20. Ver GA II, 14, p. 13. Fichte indica aqui a consciência do Eu como autor do pensamento é uma ilusão inevitável no mesmo sentido no qual Kant tinha caracterizado a ilusão transcendental como "ilusão natural" ( $C R P$, A 297/98 = B 353/54). O próprio Kant, diz Fichte, não se livrou inteiramente da "ilusão dogmática" (ver GA II, 14, p. 39), e certamente na concepção kantiana da "apercepção pura", isto é, da consciência Eu penso como condição última da unidade da experiência, revela-se ainda, segundo Fichte, uma proximidade do pensamento kantiano com o ponto de vista da lógica que na filosofia transcendental deve ser superada (ver CRP, B 131 ss.).

21. GA II, 14, p. 36. É essa tese acerca do status das determinações constitutivas da natureza que, segundo Fichte, define o sentido em que a Doutrina da Ciência essencialmente envolve um idealismo: "Isso então é a visão do idealismo que é própria da Doutrina da Ciência" (Dies ist nun die Ansicht des Idealismus der W.L. (GA II, 14, p. 37)).

22. Wäre nun hier die W.L. zu Ende, wüßte sie nicht mehr zu sagen, so wäre sie Nihilismus. ... Die Welt wäre vernichtet; nichts andres gegeben (SWV I, p. 71).

23. Ver GA III/3, 224-281, particularmente p. 245. A importância da crítica de Jacobi para o pensamento de Fichte na sua fase tardia em Berlim evidencia-se também na carta de Fichte a Jacobi do dia 3 de maio de 1810 (GA III, 6, particularmente p. 328). Para a relação da preleção do verão de 1812 com o pensamento de Jacobi, ver Ivaldo 1998.

24. Ver SWV I, p. 33.

25. ... so hat es doch gewiß sein eignes Leben (SWV I, p. 53).

26. SWV I, p. 108.

27. Ver Nuzzo 2006 e Asmuth 2012.

28. O conceito de desontologização (Desontologisierung) foi introduzido por P. Reisinger para caracterizar a função da teoria da imagem no pensamento tardio de Fichte (ver Reisinger 1979, particularmente p. 161). Para uma discussão mais recente da concepção fichteana do objeto como projeção de imagens, ver Carvalho 2014.

29. Hegel 2011, p. 180; GW 12, pp. 16 e 17.

30. Ver GW 12, p. 24.

31. Hegel 2011, p. 181; GW 12, p. 18.

32. Hegel 2011, p. 180; GW 12, p. 17.

33. Para enfatizar sua diferença com o conceito no sentido da representação abstrata, $K$. Düsing caracteriza o conceito no sentido especulativo como "universalidade não-discursiva" (nichtdiskursive Allgemeinheit) (Düsing 1995, p. 246).

34. GW 12, p. 40.

35. GW 12, p. 41.

36. Cf. Iber 2002, particularmente pp. 200-201.

37. “... we have three significant alternative positions: those of Kant, of the late Fichte, and of Hegel. And these remain open as possible philosophical approaches" (Henrich 2003, p. 300).

38. Agradeço a Júlia Sebba Ramalho e Arthur Bartholo Gomes pela revisão técnica deste artigo.

\section{RESUMOS}

In summer term 1812 Fichte lectured on "the relation of logic with real philosophy" in order to introduce the point of view of the Science of Knowledge. A few months before the beginning of Fichte's lectures, the first book of Hegel's Science of Logic had been published. Independently of 
the controversial question if Fichte's 'Transcendental Logic' from 1812 was intended to be a critical reply to the Hegelian project of a speculative logic, no doubt the lecture from summer 1812 is an important source for understanding the systematical relation between the late Fichte's conception of transcendental logic and the Hegelian project of a speculative logic. The principal thesis of this paper is that both the convergences and differences between the two philosophical projects can be identified by considering the conceptions of the concept and of selfconsciousness that are contained in Fichte's lecture and in the third part of Hegel's Lógic, the Doctrine of Concept. The comparison between these conceptions shows that the late Fichte and Hegel converge insofar as they criticize the logical conception of concepts and the idea that selfconsciousness is a fundamental principle of philosophy. However, whereas Fichte defends a genetic theory of conceptual content and of self-consciousness that is based on the conception of an absolutely spontaneous and 'image'-producing thinking, Hegel searches for a structural explanation that is based on the speculative conception of the concept as the fundamental structure of reality, understanding concepts in the logical sense as a result of the 'separation' of the original unity of the concept and self-consciousness as its conscious concretization.

ÍNDICE

Keywords: concept, self-consciousness, image

\section{AUTOR}

\section{CHRISTIAN KLOTZ}

Universidade Federal de Goiás 